\title{
Generating Evidence in the Age of COVID-19: Transmission of SARS-CoV-2 by Children
}

Jay S Kaufman, PhD

Department of Epidemiology, Biostatistics and Occupational Health, McGill University, 1020 Avenue des Pins Ouest, H3A 1A2 Montreal, Quebec, Canada. https://orcid.org/0000-0003-1606-401X

Jeremy A Labrecque, $\mathrm{PhD}$

Department of Epidemiology, Erasmus Medical Center,

Dr. Molewaterplein 50, 3015 GE Rotterdam, the Netherlands. https://orcid.org/0000-0002-1028-2158

Joanna Merckx, MD MSc

Department of Epidemiology, Biostatistics and Occupational Health, McGill University, 1020 Avenue des Pins Ouest, H3A 1A2 Montreal, Quebec, Canada. https://orcid.org/0000-0001-9426-8259

Correspondence:

Jay S. Kaufman, Ph.D

Department of Epidemiology, Biostatistics, and Occupational Health McGill University

1020 Pine Ave West

Montreal, Quebec H3A 1A2

CANADA

email: jay.kaufman@mcgill.ca

Phone: 1-514-398-7341 
FAX: 1-514-398-4503 
Abstract:

Schools worldwide were closed in response to the SARS-CoV-2 pandemic, and a key policy question involves how and when these can be re-opened. Observationally, SARS-CoV-2 seems infrequently transmitted by children, which if true argues for the feasibility of swiftly re-establishing schooling. But uncertainty and debate remains over this question. On April $28^{\text {th }}$ a manuscript was posted by the German virologist Christian Drosten (Jones et al., 2020). The manuscript asserted that viral loads in children were the same as in adults, and the authors concluded that infectiousness is therefore not a function of age. They directly connected this to the policy question of opening schools, warning sharply against doing so. This finding and its interpretation were widely disseminated in international news media and were influential in policy debates. We consider the data, analysis and interpretation of this study, especially the sample, variables measured, statistical analysis conducted, and the interpretation of these results in relation to the underlying policy question. We show that the stated conclusion is not supported, and indeed may be contradicted. Laboratory data from a small, non-representative sample were used to steer public discourse instead of adding to the scientific evidence base on the transmission dynamics of SARS-CoV-2 infection.

Funding: None

Competing interests: Dr. Merckx is employed by bioMérieux Canada as Director of Medical Affairs bioMérieux Canada, Inc.

Acknowledgements: We thank Dr Andreas Stang and Dr Jesse Papenburg for their content matter expertise and thoughtful comments on the manuscript. 
Introduction

A key policy question during the SARS-CoV-2 pandemic is the effectiveness of various lock-down measures, such as school closures. School closures have been shown to be effective in limiting influenza transmission (Jackson et al., 2013; Jackson et al., 2014), and so it was assumed by analogy that schools should also be closed to inhibit spread of SARS-CoV2. As a result, schools were shuttered in most countries of the world in early 2020, leaving over $90 \%$ of the world's children confined at home (UNESCO, 2020). Then, as countries looked for the safest ways to reopen their societies, when and how to return children to school became a central policy question. It is critical to re-establish formal education for the overall health and development of children (Esposito \& Principi, 2020) and because parents cannot work if children remain at home (Bayham \& Fenichel, 2020)). At the same time, there is widespread fear that re-opening schools could instigate an increase in the reproduction number $\mathrm{R}$ by re-establishing contacts, and thus precipitate a renewed epidemic crisis.

A key insight early in this debate was that SARS-CoV-2 might differ from influenza in being infrequently transmitted by children (Munro \& Faust, 2020). This conjecture arose from contact tracing and household studies that revealed children rarely if ever being index cases in a household, and from case studies of infected children having many contacts but few if any secondary cases. If children are infrequent active links in the transmission chain, then schools would not be major foci for increasing the $\mathrm{R}$ and spurring the epidemic. The scientific question of transmission by children therefore became a crucial policy-relevant debate.

While many scientists speculate that transmission from children, even if mildly symptomatic or asymptomatic, contributed to epidemic spread, there was still by the end of April 2020 little direct evidence of this occurring. Into this evidence vacuum came an unpublished manuscript by the renowned German virologist Christian Drosten, Director of the Institute of Virology of the Charite Universitätsmedizin in Berlin, posted on April 28 $8^{\text {th }}$ on the institute server (Jones et al., 2020). The paper asserted that viral loads in children were the same as in adults, and that this implied infectiousness was not a function of age. The paper also directly connected this to the policy question of opening schools, warning sharply that it would be dangerous to do so. Within days, this viewpoint was echoed in major media outlets. The British newspaper The Guardian showcased Drosten's paper on April 30th, with the headline "Coronavirus scientists caution against reopening schools", and quoting Drosten as saying, on the basis of his paper, "We have to caution against an unlimited reopening of schools and kindergartens in the present situation" (Devlin \& Adams, 2020). Coverage in the New York Times on May $6^{\text {th }}$ again highlighted the unpublished study and quoted Drosten as saying "I'm somehow the bringer of the bad news but I can't change the news....It's in the data." (Mandavilli, 2020)

While the Drosten paper was never peer-reviewed, it is now characteristic of the scientific response to the rapidly unfolding COVID-19 pandemic to bypass established journals and get reactions from other scientists in uncurated public debates (The Economist, May 9, 2020). We therefore offer this paper to engage in exactly this sort of critique, assessing the data, methodology and inference in the highly influential Drosten paper. These issues are critical because of the interpretation and translation of these results into information used by policymakers to make immediate decisions about the risks of reopening schools. Key concerns for consideration are the sample obtained, the variables measured, 
the statistical analysis conducted and the interpretation of these results in relation to the relevant policy implications. It is worth noting that the paper was immediately savaged on social media for the inept statistical approach reported (e.g. Egger, 2020), but that Drosten later insisted that "...the message of the paper is really unchanged by any type of more sophisticated statistical analysis" (Mandavilli, 2020). We show that this statement is dubious, and that laboratory data from a small, non-representative sample were used to steer public discourse instead of adding to the scientific evidence base on the transmission dynamics of SARS-CoV-2 infection.

\section{Is viral load a good measure of effective transmission?}

The underlying scientific question motivating the Drosten paper is whether children transmit the SARS-CoV-2 virus as effectively as adults. To answer this question, the authors compare viral loads in their study subjects. But is this the right quantity to focus on? There is no single laboratory measure that reflects effective transmission or the transmission probability of a respiratory pathogen. It remains unknown which variables play critical roles in the transmission dynamics of SARS-CoV-2 (Kissler et al., 2020; Ferreti et al., 2020), nor what function of these variables would provide a comparable measure of this quantity. Transmission dynamics and probabilities are an interaction between behavioral factors related to frequency and type of contact and of characteristics of the virus itself, the host and the environment (Halloran, 2001; van Seventer \& Hochberg, 2017).

The infectious dose for SARS-CoV-2, the minimal number of viable organisms necessary to infect a non-immune individual, remains unknown. The reference standard for viable virus infectivity is TCID50, which is the median tissue culture infective dose, an in vitro phenomenon, and is defined as the dose necessary to infect $50 \%$ of cells in culture. The method to establish this number is cumbersome, however (Loeffelholz, 2016, p. 202). High levels of viral replication are therefore measured using a more convenient proxy, the (peak) viral load expressed in copies/ml.

The viral load (VL) provides a quantitative estimate of the amount of target RNA from the clinical sample. Quantification of virus by PCR testing uses a backwards calculation of cycle threshold $(\mathrm{Ct})$ values in relation to an initial target and is expressed on the logarithmic scale (Bustin \& Mueller, 2005). The Ct value is the cycle number during the amplification phase when fluorescence of a PCR product can be detected above the background signal. The lower the Ct value, the larger the initial amount of genetic material of the virus present in the sample. Each assay needs to assess variability (Karlen et al., 2007) over the whole range of Ct and is validated against a standard curve, which varies from assay to assay (Loeffelholz, 2016, chapter 13). A good assay typically has a variability of a third of a logged unit. This intrinsic measurement variability and its effect on statistical estimation and testing was not accounted for in the Drosten study based on the erroneous argument that because this interrun variability is constant for all the runs, it is irrelevant to the comparison (Kim \& Goldberg, 2001).

Although the focus is on estimating the VL, nobody yet knows the minimal number of RNA copies per ml necessary to infect a secondary case. What defines the secondary attack rate and how much this is related to the timing or magnitude of the peak VL and the duration of shedding all remain unquantified. Wölfel et al (2020) published their assessed VL 
association with detection of viable virus, which is supposedly the assay used in the Drosten study. Considering this estimate can begin to inform a measure of infectivity, but neither infectiousness nor the transmission probability can yet be deduced. Presumably, more virus translates into increased infectivity, but there is currently no established threshold for the interpretation of measured viral loads (Patel et al., 2020) and this relationship may well vary across hosts. We do not know the magnitude in difference in absolute copy number that is clinically important for infectivity or for changes in infectiousness and transmissibility.

In addition, even with a large number of viral copies detected in the respiratory tract, transmission is by no means guaranteed. Examples of pediatric cases with high VL have been described in the peer-reviewed literature (Kam et al., 2020; Danis et al., 2020). Of course these are anecdotes of single cases, and their representativeness for the average pediatric case is unclear. One particular case resulted in a wide contact tracing effort and was published in Clinical Infectious Diseases (Danis et al., 2020). A 9 year old boy with high VL did not lead to a single secondary case, which demonstrates that high VL is not a sufficient condition that leads to high transmission and high secondary attack rate.

The specific body site where virus is located, and the duration of its presence there, as well as characteristics of contact between the infector and potential infectee are additional parameters in determining the transmission probability. It is assumed that if virus is present, a child will demonstrate behavior that facilitates transmission of the virus. Without investigation and representation of the transmission risk by contact type stratified by age of both halves of the infector-infectee pair, however, no conclusion can be drawn. More data presenting the secondary attack rate as a function of the age of the infector are necessary to further refute or confirm this assumption and yet for this pathogen remain unavailable.

\section{Design: Sample Representativeness and Generalizability}

The measured VL from a single nasal swab is not necessarily representative of the overall VL present in the respiratory tract of the child. There is considerable variation in how much virus gets into the primary sample, some of which is random and some potentially systematic. For example, nurses may in general have better swab technique than doctors. Patients may vary in how they tolerate the procedure and the quality of the swab may differ by the age of the patient (Loeffelholz, 2016, chapter 13).

Next, it has been shown that variation in VL is dependent on the specimen type and the timing when the specimen is taken from the patient in relation to initial exposure to respiratory pathogens (Charlton et al., 2018). This is equally the case for SARS-CoV-2 (Hanson et al., 2020). The respiratory specimen type, whether nasopharyngeal swab, nasal swab, nasal wash, saliva, sputum, or throat swab, determines the general performance characteristics (i.e., sensitivity and specificity) of a PCR test and the measured VL will therefore vary by specimen sample type (Hanson et al., 2020; Wyllie et al., 2020). Thus it is necessary to take into account the pre-analytical quality of samples for the diagnosis of SARSCoV-2 infection (Lippi et al., 2020). The ideal specimen type to diagnose SARS-COV-2 infection in children has not been determined and could in principle be different from the ideal specimen in adults. The Drosten paper does not even describe the specimen type utilized in this study, let alone account for this in the analysis. If the specimen type utilized has different performance in children versus adults, or if there is a propensity for taking a 
different specimen type in children compared to adults, this could bias the estimate of VL in either direction (Schmidt \& Factor, 2013; Lash et al., 2011).

Next there is the temporal variability of the VL over the disease course (Kucirka et al. 2020). A single swab is not only a sample of virus from the varying pool in the body, but also a sample in time of the varying quantity over the course of the infection (Charlton et al., 2018). The time since the patient became infected or became symptomatic is a key determinant of the true VL. Temporal variability has been reported in studies that followed VL over time, mainly in adults (Zheng et al., 2020; To et al., 2020) and in pediatric casestudies or case series (Kam et al., 2020; Xu et al., 2020; Han et al., 2020; Xing et al., 2020). The Drosten paper is entirely silent about when, in relation to infection or onset of symptoms, the respiratory samples were taken from the study participants. If children do indeed have a different clinical presentation, it may be that they are referred for testing at a different time point than adults leading to systematic differences in when the test is conducted relative to the time of infection.

It is increasingly clear that for SARS-CoV-2, there is some important fraction of adult transmission that takes place in the pre-symptomatic phase (Wei et al, 2020). It remains unclear if this is mainly because of the high peak VL at that moment or because the infector and infectee are unaware of the illness, and therefore taking no precautions against direct contact. Indeed, both mechanisms could be contributing to this pattern. Epidemiologic research has confirmed that the serial interval, the time between symptom onset in the infector and symptom onset in the infectee, is shorter than the incubation time, reflecting this pre-symptomatic transmission window (Nishiura et al., 2020; Casey et al., 2020; Tindale et al., 2020). The diligent use of laboratory data in conjunction with epidemiological investigation illustrates the real potential to learn about transmission probabilities and effective transmission in relation to the skewed curve of VL (He et al., 2020).

\section{Design: Patient Representativeness and Generalizability}

Now suppose we were able to obtain a representative measure, in space and in time, of the true VL in a child, and with proper accounting for the variability inherent in this measure. Can this estimate then provide information about the typical VL for an average child in the general population? The answer to this question rests entirely on the study design. What is the defined population of interest, and how are patients sampled from this population, according to which criteria? Sadly, the Drosten paper is entirely silent on all of these critical details as well. This is however crucially important when participants are selected into the study as a function of VL, because those with higher values are more likely to get tested and more likely to test positive. If the probability of participating in the study is also related to age in any way or if the timing of testing is related to age, this will further bias the relationship between age and VL (Griffith et al., 2020). For example, if older people were more likely to get tested or test positive in the Drosten study or simply more likely to have participated, this will bias the relationship between VL and age downward.

Remarkably, there is not even in the Drosten paper a description of the disease severity of the recruited children, neither in general nor at the moment that the sample was taken. Rather, two vague subgroups of the 47 recruited children are presented. The first group of 32 pediatric cases is sampled from the outpatient setting, about whom we know 
nothing about comorbid disease and who, for all we know, might be admitted to the hospital after their participation in the study. The second group of 15 pediatric cases are referred to as having underlying comorbid disease and hospitalization as the context in which they were tested. This represents a heterogenous group, pooling hospitalization with undifferentiated comorbidities, the latter which might or might not be associated with time since onset of disease, severity of disease or hospitalisation out of precaution. Since data on severity of disease, comorbidities and risk factors are not described in both groups of pediatric patients, nor comparably among the adults, it is impossible to assess the representativeness or generalizability of the recruited patients, nor the subgroups defined by the authors. Another study using adult data reported a 1 log-unit difference in initial VL comparing mild to severe cases, and also a similar 1 log-unit difference in peak VL comparing mild to severe cases (To et al., 2020). Moreover, To et al did not find differences in VL depending on the presence or absence of comorbidities. Yet in the Drosten paper we have no information about severity of infection.

In sum, it appears that in the Drosten study, neither the sample nor the study population are representative of any defined target population, and the estimates therefore provide no measures of any policy relevance, least of all any measure of transmission potential of one subgroup of participants in relation to another. One could at best say something about the specific patients in the study, but the lack of any study design in relation to a defined population prevents any valid inference about the nature and course of the epidemic, since epidemics, by definition, occur in populations, not in individual patients (Pearce et al., 2020).

As noted by Zhou and colleagues (2020), "Viral activity is only one of various factors that might influence disease transmission. Epidemiology is the gold standard to measure transmission potential of patients". Epidemiology entails the description of the study population, avoidance of selection bias, information bias, misclassification and assessment of possible confounders. Selection of a representative sample is a key component if one aspires to make valid population inference and recommendations. As an example of researchers who respected these scientific principles in order to advance our understanding in the current pandemic, He et al. (2020) developed infectiousness profiles based on sequential standardized sampling. Unfortunately for the specific question of the infectiousness of children, those authors did not include pediatric subjects.

\section{Statistical Inference: what is the question?}

The quality of a scientific answer can only be as good as the quality of the question posed (Kaufman \& Hernán, 2012). For any result to be meaningful, there must be a logical connection between the scientific knowledge sought, and the quality and relevance of the design, data and analysis in the service of that scientific question. In the Drosten study, the stated goal is "to examine the relationship between patient age and SARS-CoV-2 viral load," with the ultimate goal of contributing evidence to the policy question of whether schools should be reopened. It is worth taking a step back to fully appreciate the connection between the study question and the scientific question. We want to know whether infectiousness in school-aged children is low enough so that the reopening of schools is unlikely to cause increased transmission of SARS-CoV-2. As discussed above, measuring infectiousness 
directly is difficult, so the authors resort to the simpler task of targeting infectivity, and relying on estimated VL in the upper respiratory tract as a convenient proxy. If it were possible to know the relationship between VL and infectiousness, including effective transmission risk, this proxy could offer a reasonable approximation. Because this knowledge is not yet available, however, the authors engage in a "shifting of the goalpost", replacing a proxy measure of the real question with a proxy measure of a proxy question, namely, whether there is a relationship between VL and age. If VL is lower in school-aged children, the authors assert that one can then conclude that infectivity is lower in children, and therefore that reopening schools may not pose an excessive risk to society.

Ideally, to answer this proxy question, one would prefer to model the relationship between age as a continuous variable and VL as a continuous variable allowing for nonlinearities. Categorizing age introduces an arbitrariness that is not part of the natural world (i.e. the category cut-points) and discards much information by assuming that members of one category tell us nothing at all about their neighbors just on the other side of a cut-point (Altman \& Bland, 2014). Nonetheless, a carefully conducted categorical analysis can still provide a valid answer to the question, albeit with the loss of some potential precision. The most obvious categorization would be school-age children versus non-school age children, since this is the cut-point that corresponds to the underlying policy question. Only one statistical comparison is needed, the one that directly answers the question of whether VL is lower in school-aged children. Adding additional categories among school-age children could serve to detect potential differences between kindergarten, grade school and high school children, but given the very limited number of available cases among the school-aged children, this further stratification risks creating groups that are too small to support any firm inference whatsoever (Bennette \& Vickers, 2012). A multiplicity of smaller groups instead leads to many pairwise comparisons that are not relevant to the policy question at hand, such as between groups of non-school-age subjects.

\section{Statistical Inference: answering the wrong question}

A null-hypothesis significance test takes evidence produced on a continuous scale and classifies it into two categories "statistically significant" and "not statistically significant". This categorization does not correspond to demarcating the observed data into categories of "VL varies with age" and "VL does not vary with age", nor does it correspond to categories of "do not reopen schools" and "reopen schools". In fact, "significant" and "not significant" do not correspond to any of these substantively meaningful demarcations (Amrhein et al., 2019). Even if the true state of nature is that VL is lower in school-aged children, it is still entirely possible to get a non-significant result. What a null-hypothesis significance test offers is merely a procedure that produces false positives and false negatives at defined rates assuming the absence of all study biases. The false negative rate in the Drosten study would have already been ruinously high due to the inclusion of small numbers of school-aged children (Dumas-Mallet et al., 2017), which implies that any true difference in VL would have to be very large in magnitude to be declared to be "significant" in the analyses conducted (Ioannidis, 2008). Compounding this problem of low power, however, the authors conducted a large number of irrelevant tests, and then modified the significance threshold through the use of very conservative multiple testing corrections (Nakagawa, 2004). Such 
procedures were devised to protect against encountering a false positive when performing multiple tests, but they work by merely trading false positives for false negatives. The larger the number of tests performed, the greater the proportion of false negatives that arise from this "correction", which suggests the cynical strategy that if one favors a null hypothesis, one can simply perform a large enough number of tests so that it is never rejected.

For example, suppose one wishes to show that there is no correlation between age and height. All one has to do is to specify the absence of the correlation as the null hypothesis, create finely stratified groups with a small sample in each group, make a large multitude of pairwise tests, and then by correcting for this multiplicity of tests, increase the false positive rate until the null is no longer rejected. This result might then be asserted as proof of the conjecture that all humans have the same height regardless of age. This would be a crudely cynical statistical strategy, and might not survive scrutiny, but it is not far from the statistical approach found in the Drosten paper.

The authors first conduct a Kruskal-Wallis test (non-parametric ANOVA) and report the resulting p-value in relation to the null hypothesis that there is no difference in median VL between any two groups (Vargha \& Delaney, 1998). This test does not account for the natural order of the age categories, but rather treats the groups nominally. This throws away important biological knowledge and reduces the power of the test unnecessary, biasing toward a Type II error (falsely failing to reject the null). There are other non-parametric tests available that do account for order between categories, and which therefore would have greater power to reject the null. Or the authors could have used Spearman's $\rho$ with the continuous ages. While the Kruskal-Wallace procedure rejected the null of equal median VLs, the authors dismissed this result and went ahead to conduct all possible pairwise tests. With further adjustment of the significance criterion for their statistical profligacy, they finally report that the null hypothesis is not rejected, and therefore that VL does not differ by age.

It is crucial for readers of the Drosten study to recognize the fundamental statistical principle that failure to reject the null-hypothesis when conducting a significance test is not evidence in favor of the null hypothesis (i.e. absence of evidence does not correspond to evidence of absence).(Altman \& Bland, 1995) The statistical null hypothesis is merely meant to represent the prevailing scientific consensus, and so the failure to reject can at best suggest that this existing consensus cannot be overthrown on the basis of the available data. Before April 2020 there was nothing known about the relation between age and VL of SARSCoV-2. That the result of the Drosten study is reported to be "not statistically significant" is merely to say that after April 2020 there is still nothing known about the relation between age and VL of SARS-CoV-2. More importantly from a substantive perspective, rejection of this null hypothesis would not imply that opening of schools is safe, nor does failure to reject imply that it is not safe. There are many other aspects of this decision to take into consideration beyond viral load or even transmission risk such as the costs of not reopening schools to children's health and well-being (Christakis, 2020).

\section{Statistical Inference: answering the right question}

What do the reported data in the Drosten study actually tell us about the measured

viral loads of children? Consider the data shown in Table 2B (Jones et al., 2020). The authors 
report that the "Adult" mean VL of 5.16 (95\% CI: 5.05, 5.27) is not different from the "Kindergarten" mean of 4.37 (95\% CI: 3.85, 4.89). Premised on the validity of the reported Wald 95\% CI, the p-value for the comparison of these means is 0.0036 , which is by all conventional criteria considered "statistically significant" (Altman \& Bland, 2003). Another re-analysis by Held (2020) obtained a p-value of 0.045 for the same comparison using a different method, and another p-value of 0.015 for the test of linear trend across all age categories. The only reason that the authors instead report this contrast to have $p>0.05$ is because of the "correction" they make for the large number of extraneous comparisons, including comparisons between groups of adults that have no bearing on the scientific or policy question. Why should our view of the state of nature be a function of how many irrelevant comparisons were made by the authors?

In fact, these means in Table $2 \mathrm{~B}$ are $\log _{10}$ VL estimates, so the adult estimate is a mean of $10^{5.16}=144,544$ copies $/ \mathrm{ml}$ and the kindergarten estimate is a mean of $10^{4.37}=23,442$ copies $/ \mathrm{ml}$. The data displayed in the Drosten study therefore show that mean VL measured in adults is 6 times higher than in kindergarteners. The stated conclusion that these are equal is therefore wholly contradicted by the data displayed in the paper. Moreover, Dr. Drosten's statement in the New York Times interview that alternate analyses all support his stated conclusion is demonstrably false (Mandavilli, 2020).

The authors concluded their paper by stating "[T] hese data indicate that viral loads in the very young do not differ significantly from those of adults. Based on these results, we have to caution against an unlimited re-opening of schools and kindergartens in the present situation. Children may be as infectious as adults." Even with all the caveats expressed above about measures, proxies and biases, an arguably better summary could have been "These data indicate that viral loads in the very young are only one-sixth as large as those of adults. Based on these results, we have to caution against maintaining the closure of schools and kindergartens in the present situation. Children may be less infectious than adults."

\section{Conclusion}

The Drosten study, even if it had been performed, analyzed and interpreted correctly, could not provide us with an answer to the substantive question whether children generally transmit SARS-CoV-2 effectively. At most, what might be revealed by such a study is whether the measured viral load in a particular collection of patients demonstrates a relationship with age. The authors assert that no such association is observed. In the New York Times interview, Dr. Drosten apologized for this result but said that it was an inescapable fact that was "in the data". Quite to the contrary, we have shown that what is "in the data" is exactly the opposite of what is stated by the authors, that there is in fact a large contrast in the measured values between groups. This large difference was deemed "not statistically significant" by the authors due to the analytic choices they made, perhaps ineptly, but there is no sense in which this null finding is "in the data".

While the Drosten study may not resolve the scientific and policy questions that it sought to address, it does reveal something about how science is working in the chaotic context of this rapidly evolving pandemic. The Drosten manuscript made an enormous splash in the media, where it continues to be cited authoritatively while still awaiting the benefit of formal peer review (Mallapaty, 2020). The prominent senior author is a media 
celebrity, who advises the German government and records a twice-weekly podcast that had received over 34 million plays by the end of April (The Economist, April 30, 2020). The journal Science referred to him as a "cult figure" who has as much popular influence during the pandemic as the German Chancellor (Kupferschmidt, 2020). He has used this notoriety to weigh in strongly on the policy question around school reopening, and justifying his concerns with this study's argument that children are just as contagious as adults. Rather than simply being a question of viral load, however, the school reopening policy question is a complex one that requires balancing competing harms in the broader context of fear and uncertainty (Crawley et al., 2020).

This whole incident therefore raises troubling broader questions about information and misinformation at critical policy-making junctures, how scientific consensus is achieved in periods of crisis when normative institutions fail to keep up with the pace of the unfolding emergency, and how even scientists can be so readily swayed by statistical sleight-of-hand, or star-struck by big name authors so that they trust stated conclusions without delving into the thorny details. Science is a social process, and ideally, a self-correcting one. It is nourished by earnest criticism and the sincere common purpose of understanding the natural world, so that this evolving knowledge can best serve humanity. 


\section{References:}

Altman DG, Bland JM. Absence of evidence is not evidence of absence. BMJ. 1995;311(7003):485. doi:10.1136/bmj.311.7003.485

Altman DG, Bland JM. Interaction revisited: the difference between two estimates. BMJ. 2003;326(7382):219. doi:10.1136/bmj.326.7382.219

Altman DG. Categorizing continuous variables. Wiley StatsRef: Statistics Reference Online. 2014 Apr 14.

Amrhein V, Greenland S, McShane B. Scientists rise up against statistical significance. Nature. 2019;567(7748):305-307. doi:10.1038/d41586-019-00857-9

Bayham J, Fenichel EP. Impact of school closures for COVID-19 on the US health-care workforce and net mortality: a modelling study. Lancet Public Health. 2020;5(5):e271e278. doi:10.1016/S2468-2667(20)30082-7

Bennette C, Vickers A. Against quantiles: categorization of continuous variables in epidemiologic research, and its discontents. BMC medical research methodology. 2012 Dec 1;12(1):21.

Bustin SA, Mueller R. Real-time reverse transcription PCR (qRT-PCR) and its potential use in clinical diagnosis. Clinical Science. 2005 Oct 1;109(4):365-79.

Casey M, Griffin J, McAloon CG, Byrne AW, Madden JM, McEvoy D, Collins AB, Hunt K, Barber A, Butler F, Lane EA. Estimating pre-symptomatic transmission of COVID-19: a secondary analysis using published data. medRxiv. 2020 Jan 1.

Charlton CL, Babady E, Ginocchio CC, Hatchette TF, Jerris RC, Li Y, Loeffelholz M, McCarter YS, Miller MB, Novak-Weekley S, Schuetz AN. Practical guidance for clinical microbiology laboratories: viruses causing acute respiratory tract infections. Clinical microbiology reviews. 2018 Dec 19;32(1):e00042-18.

Christakis DA. School Reopening-The Pandemic Issue That Is Not Getting Its Due [published online ahead of print, 2020 May 13]. JAMA Pediatr. 2020;

10.1001/jamapediatrics.2020.2068

Crawley E, Loades M, Feder G, Logan S, Redwood S, Macleod J. Wider collateral damage to children in the UK because of the social distancing measures designed to reduce the impact of COVID-19 in adults. BMJ Paediatr Open. 2020;4(1):e000701. Published 2020 May 4. doi:10.1136/bmjpo-2020-000701

Danis K, Epaulard O, Bénet T, Gaymard A, Campoy S, Bothelo-Nevers E, BouscambertDuchamp M, Spaccaferri G, Ader F, Mailles A, Boudalaa Z. Cluster of coronavirus disease 2019 (Covid-19) in the French Alps, 2020. Clinical Infectious Diseases. 2020 Apr 11.

Devlin H, Adams R. Coronavirus: scientists caution against reopening schools. The Guardian (UK), Thu 30 Apr 202016.45 BST

[https://www.theguardian.com/world/2020/apr/30/coronavirus-scientists-cautionagainst-reopening-schools, accessed May 20, 2020]

Dumas-Mallet E, Button KS, Boraud T, Gonon F, Munafò MR. Low statistical power in biomedical science: a review of three human research domains. R. Soc. open sci. 2017; 4160254. doi.org/10.1098/rsos.160254

The Economist. Europe. Christian Drosten, Germany's covid-19 explainer-in-chief. April 30, 2020. [https://www.economist.com/europe/2020/04/30/christian-drostengermanys-covid-19-explainer-in-chief, accessed, May 20, 2020] 
The Economist. Leaders. Speeding up science during the pandemic. May 9, 2020.

[https://www.economist.com/leaders/2020/05/09/speeding-up-science-during-thepandemic, accessed, May 20, 2020]

Esposito S, Principi N. School Closure During the Coronavirus Disease 2019 (COVID-19)

Pandemic: An Effective Intervention at the Global Level? [published online ahead of print, 2020 May 13]. JAMA Pediatr. 2020;10.1001/jamapediatrics.2020.1892.

doi:10.1001/jamapediatrics.2020.1892

Ferretti L, Wymant C, Kendall M, Zhao L, Nurtay A, Abeler-Dörner L, Parker M, Bonsall D, Fraser C. Quantifying SARS-CoV-2 transmission suggests epidemic control with digital contact tracing. Science. 2020 May 8;368(6491).

Griffith G, Morris TT, Tudball M, Herbert A, Mancano G, Pike L, Sharp GC, Palmer TM, Smith GD, Tilling K, Zuccolo L. Collider bias undermines our understanding of COVID-19 disease risk and severity. medRxiv. 2020 Jan 1.

Halloran ME. Concepts of transmission and dynamics. Thomas JC, Thomas JC, Weber DJ, editors. Epidemiologic methods for the study of infectious diseases. Oxford University Press; 2001 Mar 22;56:85.

Han MS, Seong MW, Heo EY, Park JH, Kim N, Shin S, Cho SI, Park SS, Choi EH. Sequential analysis of viral load in a neonate and her mother infected with SARS-CoV-2. Clinical Infectious Diseases. 2020 Apr 16.

Hanson KE, Caliendo AM, Arias CA, Englund JA, Lee MJ, Loeb M, Patel R, El Alayli A, Kalot MA, Falck-Ytter Y, Lavergne V. Infectious Diseases Society of America Guidelines on the Diagnosis of COVID-19. Published by IDSA, 5/6/2020.

He X, Lau EH, Wu P, Deng X, Wang J, Hao X, Lau YC, Wong JY, Guan Y, Tan X, Mo X. Temporal dynamics in viral shedding and transmissibility of COVID-19. Nature medicine. 2020 Apr 15:1-4.

Held L. A discussion and reanalysis of the results reported in Jones et al.(2020). Working Paper. University of Zurich. arXiv. 2005.10237v1 [stat.AP] 20 May 2020

Ioannidis JP. Why most discovered true associations are inflated. Epidemiology. 2008 Sep 1:640-8.

Jackson C, Mangtani P, Hawker J, Olowokure B, Vynnycky E. The effects of school closures on influenza outbreaks and pandemics: systematic review of simulation studies. PLoS One. 2014;9(5):e97297. Published 2014 May 15. doi:10.1371/journal.pone.0097297

Jackson C, Vynnycky E, Hawker J, Olowokure B, Mangtani P. School closures and influenza: systematic review of epidemiological studies. BMJ Open. 2013;3(2):e002149. Published 2013 Feb 26. doi:10.1136/bmjopen-2012-002149

Jones TC, Mühlemann B, Veith T, Zuchowski M, Hofmann J, Stein A, Edelmann A, Corman VM, Drosten C. An analysis of SARS-CoV-2 viral load by patient age. German Research network Zoonotic Infectious Diseases website. 2020.

[https://zoonosen.charite.de/fileadmin/user_upload/microsites/m_cc05/virologieccm/dateien_upload/Weitere_Dateien/analysis-of-SARS-CoV-2-viral-load-by-patientage.pdf, accessed May 20, 2020]

Kam KQ, Yung CF, Cui L, Tzer Pin Lin R, Mak TM, Maiwald M, Li J, Chong CY, Nadua K, Tan NW, Thoon KC. A well infant with coronavirus disease 2019 with high viral load. Clinical Infectious Diseases. 2020.

Karlen Y, McNair A, Perseguers S, Mazza C, Mermod N. Statistical significance of quantitative PCR. BMC bioinformatics. 2007 Dec 1;8(1):131. 
Kaufman JS, Hernán MA. Epidemiologic methods are useless: they can only give you answers. Epidemiology. 2012;23(6):785-786. doi:10.1097/EDE.0b013e31826c30e6

Kim MY, Goldberg JD. The effects of outcome misclassification and measurement error on the design and analysis of therapeutic equivalence trials. Statistics in medicine. 2001 Jul 30;20(14):2065-78.

Kissler SM, Tedijanto C, Goldstein E, Grad YH, Lipsitch M. Projecting the transmission dynamics of SARS-CoV-2 through the post-pandemic period. Science. 2020 Apr 14.

Kucirka LM, Lauer SA, Laeyendecker O, Boon D, Lessler J. Variation in False-Negative Rate of Reverse Transcriptase Polymerase Chain Reaction-Based SARS-CoV-2 Tests by Time Since Exposure [published online ahead of print, 2020 May 13]. Ann Intern Med. 2020;10.7326/M20-1495. doi:10.7326/M20-1495

Kupferschmidt K. How the pandemic made this virologist an unlikely cult figure. Science 2020 (April 28); [https://www.sciencemag.org/news/2020/04/how-pandemic-madevirologist-unlikely-cult-figure, accessed, 20 May 2020]

Lash TL, Fox MP, Fink AK. Applying quantitative bias analysis to epidemiologic data. Springer Science \& Business Media; 2011, pp. 103-106.

Lippi G, Simundic AM, Plebani M. Potential preanalytical and analytical vulnerabilities in the laboratory diagnosis of coronavirus disease 2019 (COVID-19). Clinical Chemistry and Laboratory Medicine (CCLM). 2020 Mar 16;1(ahead-of-print).

Loeffelholz M. Clinical virology manual. John Wiley \& Sons; 2016.

Mallapaty S. How do children spread the coronavirus? The science still isn't clear. Nature 2020; 581: 127-8. doi: 10.1038/d41586-020-01354-0

Mandavilli A. Cases Could Soar as Evidence Shows Children Can Transmit Virus. The New York Times, May 6, 2020, Section A, Page 17 [https://www.nytimes.com/2020/05/05/health/coronavirus-children-transmissionschool.html, accessed May 20, 2020]

Matthias \#WashYourHands Egger, @eggersnsf, May 6 [https://twitter.com/eggersnsf/status/1257993188943572993?s=20, accessed May 20, 2020]

Munro APS, Faust SN. Children are not COVID-19 super spreaders: time to go back to school. Archives of Disease in Childhood Published Online First: 05 May 2020. doi: 10.1136/archdischild-2020-319474

Nakagawa S. A farewell to Bonferroni: the problems of low statistical power and publication bias. Behavioral ecology. 2004 Nov 1;15(6):1044-5.

Nishiura H, Linton NM, Akhmetzhanov AR. Serial interval of novel coronavirus (COVID-19) infections. International journal of infectious diseases. 2020 Mar 4.

Patel R, Babady E, Theel ES, Storch GA, Pinsky BA, George KS, Smith TC, Bertuzzi S. Report from the American Society for Microbiology COVID-19 international summit, 23 march 2020: value of diagnostic testing for SARS-CoV-2/COVID-19.

Pearce N, Vandenbroucke JP, VanderWeele TJ, Greenland S. Accurate Statistics on COVID-19 Are Essential for Policy Guidance and Decisions. American Journal of Public Health 2020, e1_e3. doi.org/10.2105/AJPH.2020.305708

Schmidt RL, Factor RE. Understanding sources of bias in diagnostic accuracy studies. Arch Pathol Lab Med. 2013;137(4):558-565. doi:10.5858/arpa.2012-0198-RA 
Tindale L, Coombe M, Stockdale JE, Garlock E, Lau WY, Saraswat M, Lee YH, Zhang L, Chen D, Wallinga J, Colijn C. Transmission interval estimates suggest pre-symptomatic spread of COVID-19. MedRxiv. 2020 Jan 1.

To KK, Tsang OT, Leung WS, Tam AR, Wu TC, Lung DC, Yip CC, Cai JP, Chan JM, Chik TS, Lau DP. Temporal profiles of viral load in posterior oropharyngeal saliva samples and serum antibody responses during infection by SARS-CoV-2: an observational cohort study. The Lancet Infectious Diseases. 2020 Mar 23.

UNESCO. COVID-19 Educational Disruption and Response [https://en.unesco.org/covid19/educationresponse, accessed May 20, 2020]

van Seventer JM, Hochberg NS. Principles of Infectious Diseases: Transmission, Diagnosis, Prevention, and Control. International Encyclopedia of Public Health. 2017:22.

Vargha A, Delaney HD. The Kruskal-Wallis Test and Stochastic Homogeneity. Journal of Educational and Behavioral Statistics 1998; 23(2), 170-192. doi.org/10.3102/10769986023002170

Wei WE, Li Z, Chiew CJ, Yong SE, Toh MP, Lee VJ. Presymptomatic Transmission of SARSCoV-2-Singapore, January 23-March 16, 2020. Morbidity and Mortality Weekly Report. 2020 Apr 10;69(14):411.

Wölfel R, Corman VM, Guggemos W, Seilmaier M, Zange S, Müller MA, Niemeyer D, Jones TC, Vollmar P, Rothe C, Hoelscher M. Virological assessment of hospitalized patients with COVID-2019. Nature. 2020 Apr 1:1-5.

Wyllie AL, Fournier J, Cassanovas-Massana A, Campbell M, Tokuyama M, Vijayakumar P, Geng B, Muenker MC, Moore AJ, Vogels, CBF, Petrone ME, Ott IM et al. Saliva is more sensitive for SARS-CoV-2 detection in COVID-19 patients than nasopharyngeal swabs. medRxiv preprint. 2020 Apr 16. doi.org/10.1101/2020.04.16.20067835.

Xing YH, Ni W, Wu Q, Li WJ, Li GJ, Wang WD, Tong JN, Song XF, Wong GW, Xing QS. Prolonged viral shedding in feces of pediatric patients with coronavirus disease 2019. Journal of Microbiology, Immunology and Infection. 2020 Mar 28.

Xu Y, Li X, Zhu B, Liang H, Fang C, Gong Y, Guo Q, Sun X, Zhao D, Shen J, Zhang H. Characteristics of pediatric SARS-CoV-2 infection and potential evidence for persistent fecal viral shedding. Nature medicine. 2020 Apr;26(4):502-5.

Zheng S, Fan J, Yu F, Feng B, Lou B, Zou Q, Xie G, Lin S, Wang R, Yang X, Chen W. Viral load dynamics and disease severity in patients infected with SARS-CoV-2 in Zhejiang province, China, January-March 2020: retrospective cohort study. bmj. 2020 Apr $21 ; 369$.

Zhou F, Fan G, Liu Z, Cao B. SARS-CoV-2 shedding and infectivity - Authors' reply. Lancet. 2020;395(10233):1340. doi:10.1016/S0140-6736(20)30869-2 